\title{
Management of cutaneous discomfort in patients with scleroderma: a clinical trial
}

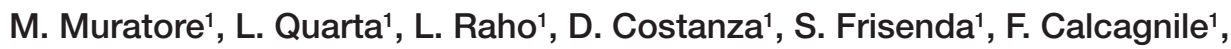 \\ A. Grimaldi' ${ }^{1}$ E. Quarta ${ }^{1}$, D. Carati ${ }^{2}$, M. Guido ${ }^{3}$, A. Zizza ${ }^{4}$, G. Alessandrini ${ }^{5}$ \\ 'Department of Rheumatology, "A. Galateo" Hospital, San Cesario di Lecce (LE); \\ ${ }^{2}$ Research and Development Department, Ekuberg Pharma srl, Martano (LE); \\ ${ }^{3}$ Laboratory of Hygiene, Department of Biological and Environmental Sciences and Technologies, \\ University of Salento, Lecce; ${ }^{4}$ nstitute of Clinical Physiology, National Research Council, Lecce; \\ ${ }^{5}$ Dermatologist, Ugento (LE), Italy
}

\begin{abstract}
SUMMARY
Systemic sclerosis (scleroderma) is a disease of unknown cause, the hallmark of which is induration of the skin. This bad condition of the skin influences negatively the quality of life of patients with scleroderma. The aim of the study was to verify the efficacy of two formulations, specifically designed to wash, moisturize and soothe the scleroderma skin. An independent, randomized, double blind, controlled trial was conducted in the Department of Rheumatology of "A. Galateo" Hospital in San Cesario di Lecce. Forty-six women affected by scleroderma, and treated with Iloprost every month, were divided into two groups: group 1 followed a specific treatment with cleansing formulation only, group 2 followed a combined treatment with the cleansing solution and the moisturizing solution. In addition, a third group was evaluated: 14 women, who did not undergo intravenous Iloprost therapy, were treated simultaneously with the cleansing formulation and the moisturizing formulation. The three treatments lasted for 4 weeks. Reduction in trans epidermal water loss (TEWL), increase in moisturization of the stratum corneum, reduction in Skin Score and improvement in quality of life were assessed. Very significant improvement in quality of life occurred in each group. Group 2 obtained very significant improvement in hydration and reduction in skin score and TEWL.

The study showed that the daily use of both formulations proved to be effective in washing, hydrating and soothing the skin of patients with scleroderma, especially in association with Iloprost therapy.
\end{abstract}

Key words: Systemic sclerosis, Skin care, Trans epidermal water loss (TEWL) test.

Reumatismo, 2013; 65 (5): 240-247

\section{INTRODUCTION}

ystemic sclerosis $(\mathrm{SSc})$ is a connectivetissue disease characterized by excessive collagen deposition and by vascular hyper-reactivity and obliterative microvascular phenomena $(1,2)$. SSc can affect different organs, such as the skin, tendons, joints, blood vessels and visceral organs, resulting in possible disabilities (3) and increasing mortality risk (4). Indeed, the term scleroderma, coined by Gintrac in 1847 (5), arose from the importance of skin involvement in the disease with vascular and fibrotic changes.

Corresponding author: Maurizio Muratore Department of Rheumatology, "A. Galateo" Hospital 73016 San Cesario di Lecce (LE), Italy E-mail: mamuratore@libero.it
Three phases of dermal involvement have been described. Firstly, there is an edematous phase, often presenting stiff and swollen hands and fingers. The second phase, called indurative phase, is characterized by thickening and induration of the skin. Here, sclerodactyly and the classic expressionless face make the diagnosis unmistakable. Ultimately, an atrophic phase occurs, when the skin may actually soften (6). Telangiectasias are commonly found on the hands and the face, especially in the limited cutaneous systemic sclerosis (7). Calcinosis occurs commonly on the volar aspect of the fingertips and over joints such as the metacarpophalangeal and interphalangeal joints, where it may ulcerate (8). Painful digital ulcers that generally occur on the fingertips as a result of local ischemia and vascular insufficiency are a frequent complication $(9,10)$. Other common skin manifestations of SSc include hypo- and hyper- pigmented areas of the skin, loss of 
hair follicles and loss of sebaceous glands (anhidrosis) with resultant dryness. Pruritus associated with dry skin can be intensely irritating and bothersome to SSc patients (10). All these skin manifestations strongly influence the daily life of patients affected by SSc.

Many vitamins, hormones, pharmaceutical drugs and surgical procedures have been reported to be successful in the treatment of systemic sclerosis. Almost all of these treatments have been received with great enthusiasm, but later abandoned after more rigorous and critical scientific evaluation (11). Iloprost, a stable prostacyclinmimetic drug, is widely prescribed to treat vascular features of SSc (Raynaud's phenomenon, digital ulcers and pulmonary arterial hypertension) on the grounds of its well known vasodilatory and antiaggregant effects. Besides these actions, Iloprost appears to have also an antioxidant effect that substantially adds on to the spectrum of its non-conventional (e.g. antifibrotic and angiogenic) actions $(12,13)$. Simple but important treatment measures for patients with scleroderma include physical therapy and regular exercise to maintain circulation, joint flexibility and muscle strength (14). Topical steroids, topical calcineurin inhibitors, systemic steroids and/or systemic immunosuppressive therapy with drugs such as MTX, cyclophosphamide, cyclosporin and D-penicillamine have been used with varying success to reduce skin hardening (15-17).

Nowadays, there are no specific solutions to treat the skin of patients with scleroderma in terms of cleanliness and hydration. Recently, a pilot study of mycophenolate mofetil combined with intravenous methylprednisolone pulses and oral low-dose glucocorticoids has demonstrated to significantly improve the values of the Modified Rankin Scale and the quality of life in patients with extensive skin disease (18). Hydrating products are effective at reducing the signs and symptoms of dry skin (19) and they are able to maintain skin integrity and well being. They are recommended as a fundamental component in the care of normal skin, but also of the skin character- ized by an alteration of the epidermal barrier and a decrease in water content of the stratum corneum (20).

\section{MATERIALS AND METHODS}

This study was conducted in the Department of Rheumatology, Hospital "A. Galateo", San Cesario di Lecce, Italy, during the months of May, June and July in 2012, as an independent, randomized, double blind controlled trial, according to the ethical principles contained in the Declaration of Helsinki.

Inclusion criteria: patients affected by SSc under Iloprost therapy and patients affected by SSc who do not undergo Iloprost therapy, aged $>18$ years.

Exclusion criteria: pregnant women, known allergies to one of the ingredients of the two formulations under investigation, presence of skin ulcers and excessive use of tobacco (>3-5 cigarettes a day) or alcohol ( $>2$ glasses of wine or beer). The study was approved by the local ethical committee and an informed consent was obtained from each subject enrolled before topic administration.

Sixty women were admitted to participate to the trial, all affected by diffuse SSc. Mean age was 50.2 years \pm 8.4 with a range from 25 to 68 years; mean duration of disease was 6.4 years \pm 2.2 , with a range from 4 to 15 years. The antinuclear antibody test and anti-topoisomerase I (Anti-Scl-70) was positive in all patients. Forty-six women, usually treated with Iloprost infusion for 1 day-a-month (a vial of Iloprost $0.05 \mathrm{mg} / 0.5$ $\mathrm{mL}$ was dissolved in $250 \mathrm{cc}$ of physiological solution and administered with an infusional pump at $30 \mathrm{~mL}$ per hour, $8 \mathrm{~h}$ per day), were selected and treated with the two formulations intended to provide an effective treatment for dry skin and able to improve the quality of life of the patients. Moreover, a third group of 14 women that do not undergo Iloprost therapy was investigated.

Each group followed a specific treatment:

- Group 1: 22 women, under Iloprost therapy, underwent treatment with the cleans- 
ing formulation only twice a day, for four weeks. The product was applied on the face, on the hands (in particular on the volar part of the right forearm) and on the body.

- Group 2: 24 women, under Iloprost therapy, underwent treatment with the cleansing formulation and the moisturizing formulation even twice a day, for four weeks. The product was applied on the face, on the hands (in particular on the volar part of the right forearm) and on the body.

- Group 3: 14 women, who did not follow Iloprost therapy, underwent treatment with the cleansing formulation and the moisturizing formulation twice a day, for four weeks. The product was applied on the face, on the hands (in particular on the volar part of the right forearm) and on the body.

For each group the skin score at baseline was calculated: Group 1 (1.0-0.4), Group 2 (1.2-0.3), Group III (1.2-03). Data are expressed as mean \pm SD (Tab. I).

In particular, the two formulations used differently by the patients were:

A cleansing formulation based on Melia Azadirachta Leaf extract (CAS number 84696-25-3) and biosaccharide-gum-1, a polysaccharide made by fermenting plants. It is able to bind water to the epidermis and to create a moisturizing film on the skin that makes it soft. In addition, it provides a long lasting hydration and an anti-irritant action; A moisturizing cream based on natural actives as Prunus amygdalus dulcis oil (CAS number 8007-69-0), Triticum vulgare germ oil (CAS number 68917-73-7), Butyrospermum parkii butter (CAS number 194043-92-0), tocopheryl acetate (CAS number 7695-91-2), bisabolol (CAS number 515-69-5), ceramide III (CAS number 100403-19-8), Argania spinosa kernel oil (CAS number 223747-87-3) and a bio- technological derivative called dihydroavenanthramide (CAS number 697235) with moisturizing and soothing action, which helps relieve irritated skin.

Hydration and protective efficacy were assessed by the evaluation of the hydration index (Moisture) and of the water evaporation index (measurement of trans epidermal water loss (TEWL). They were both measured using DermaLab TEWL and Moisture probes (Cortex technology, Hadsund, Denmark) and they were analyzed using the software DermaLab USB, version 1.09. TEWL measurement is based upon the vapor gradient principle (open chamber). The open chamber design maintains the free natural evaporation from the surface without interfering with the environment over the measurement area, thus ensuring unbiased and accurate readings. With reference to Moisture measurement, DermaLab uses a conductance measurement principle to measure the water binding capacity of the stratum corneum.

These measurements were carried out on the volar part of the right forearm. The application area, around $6 \mathrm{~cm}^{2}$, has been delimited with surgical tape. Moreover, the patients acclimatized for $30 \mathrm{~min}$ in a room at controlled temperature and humidity (20-22 ${ }^{\circ} \mathrm{C}, 40-50 \%$ of relative humidity).

The level of cutaneous damage was evaluated using a semi-quantitative method called Modified Rodnan skin thickness test: 17 cutaneous sites were investigated objectively thanks to clamping of the skin, giving a score from 0 to 3 to each area (21). This analysis has been carried out by the team of physicians involved in the study. A specific questionnaire called dermatology life quality index (DLQI), according to Finlay et al. (22), was administered in order to assess the improvement in the

Table I - Comparison of skin score, trans epidermal water loss and moisture in the three groups of subjects at T0, T1 and T2. Data are expressed as mean \pm SD.

\begin{tabular}{|l|l|l|l|l|l|l|l|l|l|l|}
\hline Analysis & \multicolumn{3}{|c|}{ Group 1 } & \multicolumn{3}{c|}{ Group 2 } & \multicolumn{3}{c|}{ Group 3 } & P \\
\hline & Baseline $\left(\mathrm{T}_{\mathbf{0}}\right)$ & $\mathrm{T}_{1}$ & $\mathrm{~T}_{2}$ & Baseline $\left.\mathbf{T}_{\mathbf{0}}\right)$ & $\mathrm{T}_{1}$ & $\mathrm{~T}_{2}$ & Baseline $\left(_{0}\right)$ & $\mathrm{T}_{1}$ & $\mathrm{~T}_{2}$ & \\
\hline Skin score & $1.0 \pm 0.4$ & $0.9 \pm 0.4$ & $1.2 \pm 0.3$ & $1.0 \pm 0.3$ & $1.2 \pm 0.3$ & $1.0 \pm 0.3$ & 0.2812 & & & \\
\hline TEWL & $7.3 \pm 2.1$ & $6.6 \pm 1.5$ & $6.4 \pm 1.5$ & $6.4 \pm 1.9$ & $5.9 \pm 1.7$ & $5.3 \pm 1.6$ & $6.3 \pm 1.8$ & $5.9 \pm .7$ & $5.0 \pm 1.1$ & 0.2870 \\
\hline Moisture & $209.0 \pm 44.5$ & $248.9 \pm 47.1$ & $235.4 \pm 51.9$ & $159.7 \pm 53.8$ & $190.2 \pm 48.0$ & $189.7 \pm 45.6$ & $152.9 \pm 28.6$ & $172.9 \pm 28.6$ & $182.0 \pm 32.5$ & 0.0012 \\
\hline
\end{tabular}

TEWL, trans epidermal water loss. 
quality of life. Three different times of assessment were identified for instrumental evaluations (TEWL and Moisture): T0, before starting the treatment; T1, one hour after the first application (short term test); T2, after 28 days (long term test).

Skin score and DLQI questionnaire were evaluated at $\mathrm{T} 0$ and $\mathrm{T} 2$.

With reference to group 1 and group 2, instrumental evaluations have been done at least 10 days after the previous intravenous Iloprost therapy.

\section{Statistical analysis}

One-way analysis of variance (ANOVA) was used to examine differences between groups on different examination times. Within groups, analyses of the statistical changes from the baseline were performed using the paired T-test. In all cases, the Kolmogorov-Smirnov test was applied to test for a normal distribution. Statistical analyses were performed with MedCalc software, version 11.4.1.0, and P-values $<0.05$ were considered significant.

\section{RESULTS}

Obtained results from TEWL measurements showed significant improvement in group $2(\mathrm{P}=0.0243)$ and highly significant improvement in group $3(\mathrm{P}<0.0010)$ one hour after the first treatment (short term test). In the long-term test, after 28 days of treatment, highly significant reduction in TEWL has been observed in group 2 $(\mathrm{P}=0.0006)$ and in group $3(\mathrm{P}=0.0019)$ and significant reduction in group $1(\mathrm{P}=0.0353)$ (Fig. 1).

Group 1 showed highly significant improvement in the ability of the stratum corneum to bind water after one hour $(\mathrm{P}=0.0068)$, and significant improvement after one month ( $\mathrm{P}=0.0314)$ (Fig. 2). Highly significant improvement has been reported in group 2 and group 3 after one hour $(\mathrm{P}<0.0004$ and $\mathrm{P}<0.0000$, respectively) and one month of treatment $(\mathrm{P}=0.0001$, respectively) (Fig. 2).

Skin scores analysis showed statistically significant improvement in group 1

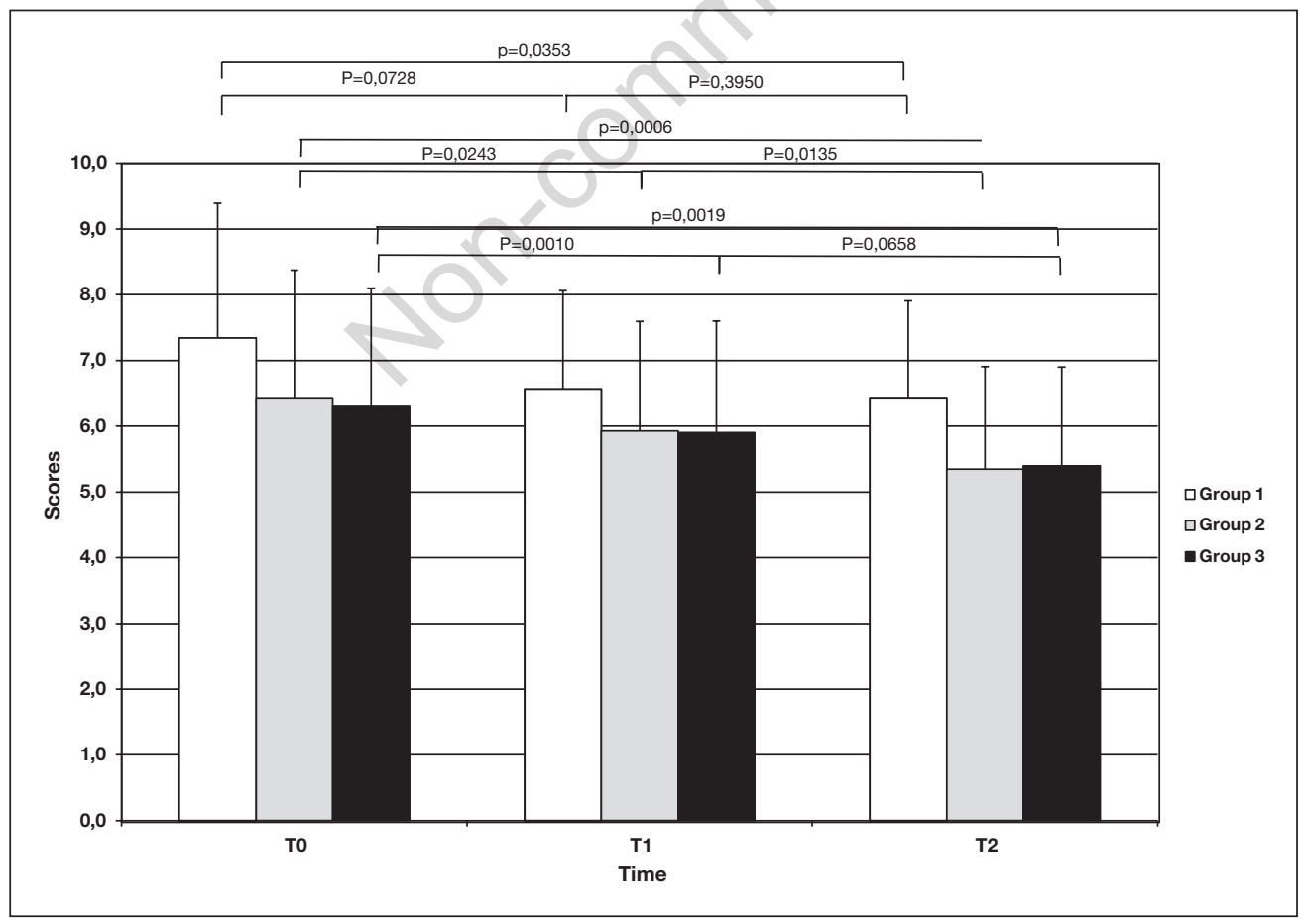

Figure 1 - Level of trans epidermal water loss in the three groups after one hour of treatment (short term test) and after one month of treatment (long term test) (data are expressed as mean score \pm SEM). 
$(\mathrm{p}=0.0156)$ and highly significant improvement in group $2(\mathrm{P}<0.0001)$ (Fig. 3).

DLQI showed highly significant reduction
$(\mathrm{P}<0.0001)$ of indexes in all the three study groups (Fig. 4). The analysis of variance for the skin score, TEWL and Moisture

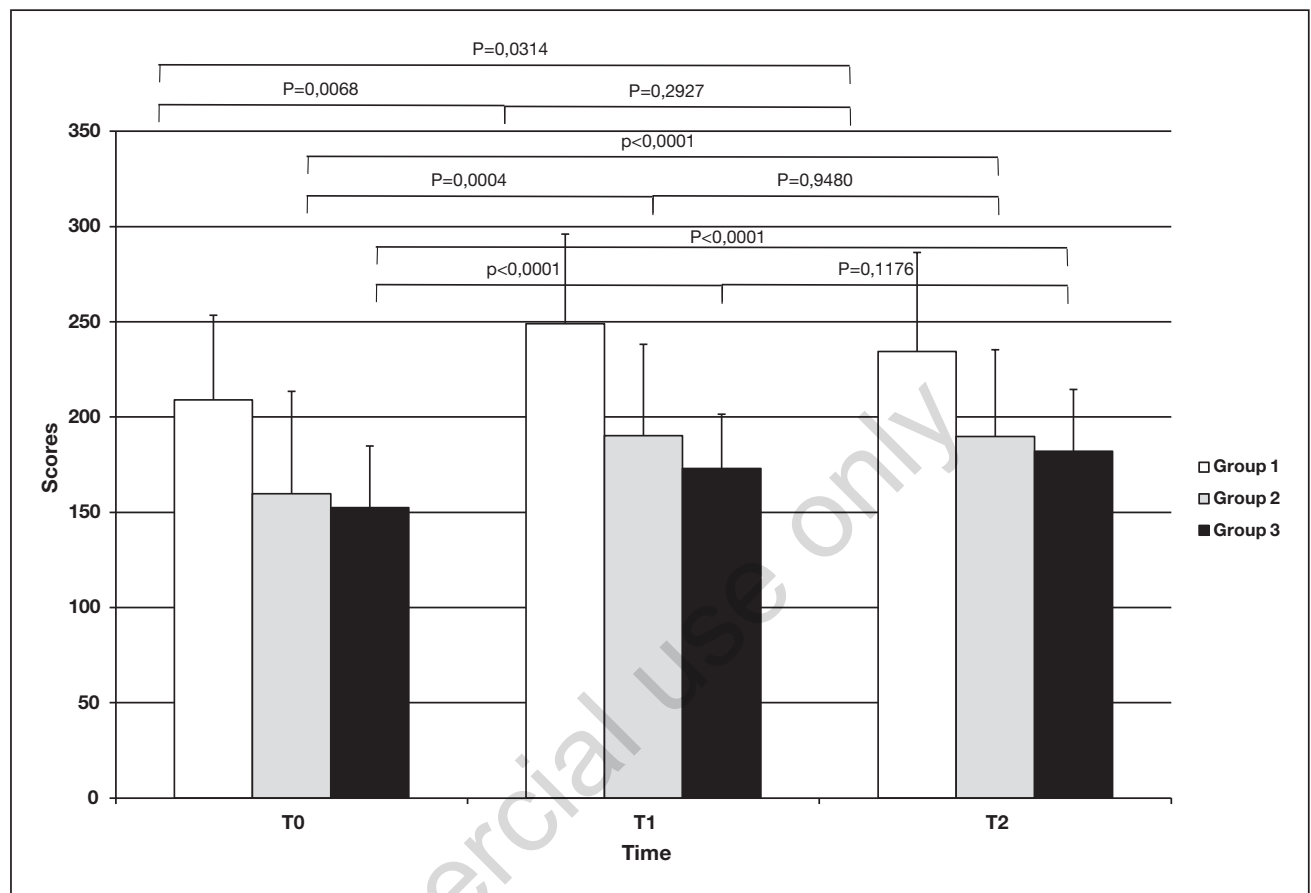

Figure 2 - Level of hydration of the stratum corneum of the skin (Moisture) in the three groups after one hour of treatment (short term test) and after one month of treatment (long term test) (data are expressed as mean score \pm SEM).

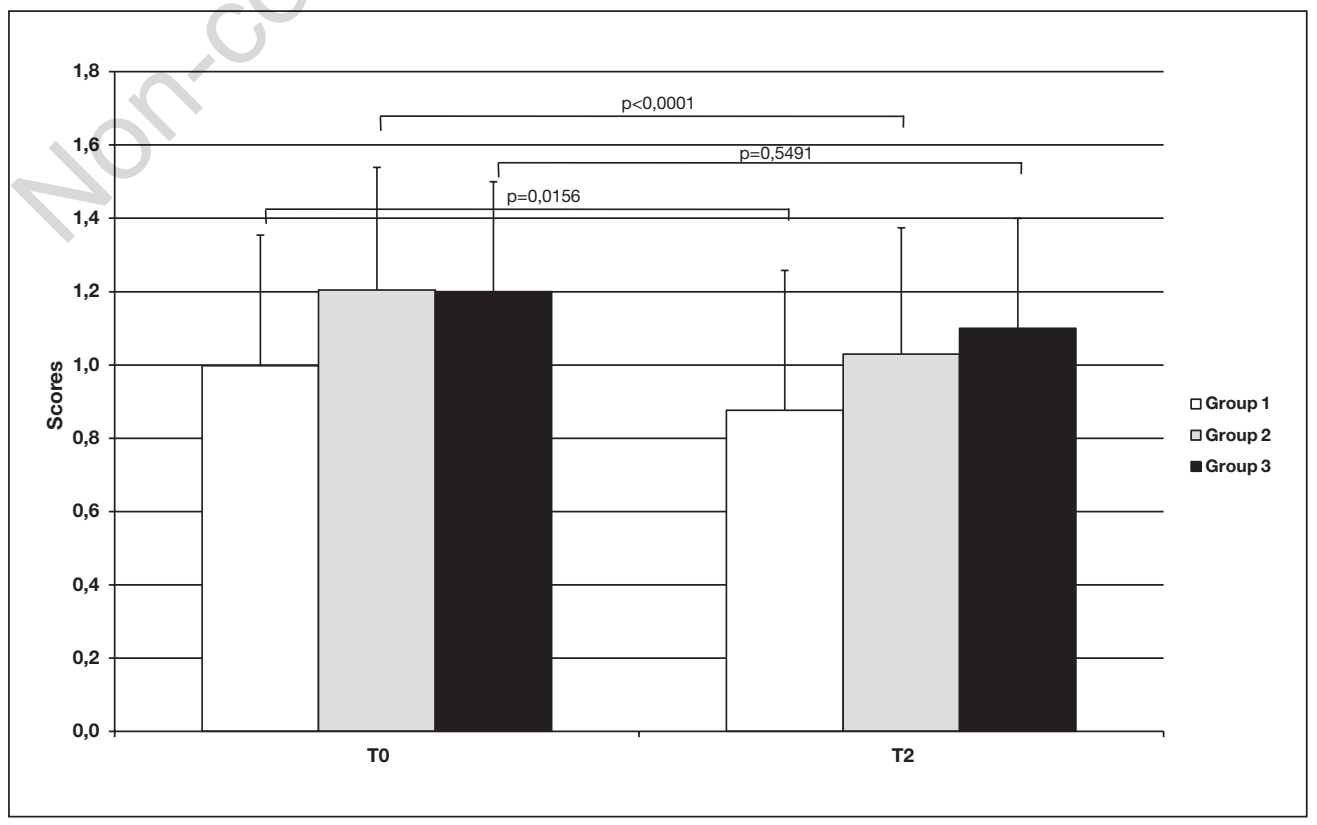

Figure 3 - Skin score results obtained in the three groups after one month of treatment (long term test) (data are expressed as mean score \pm SEM). 


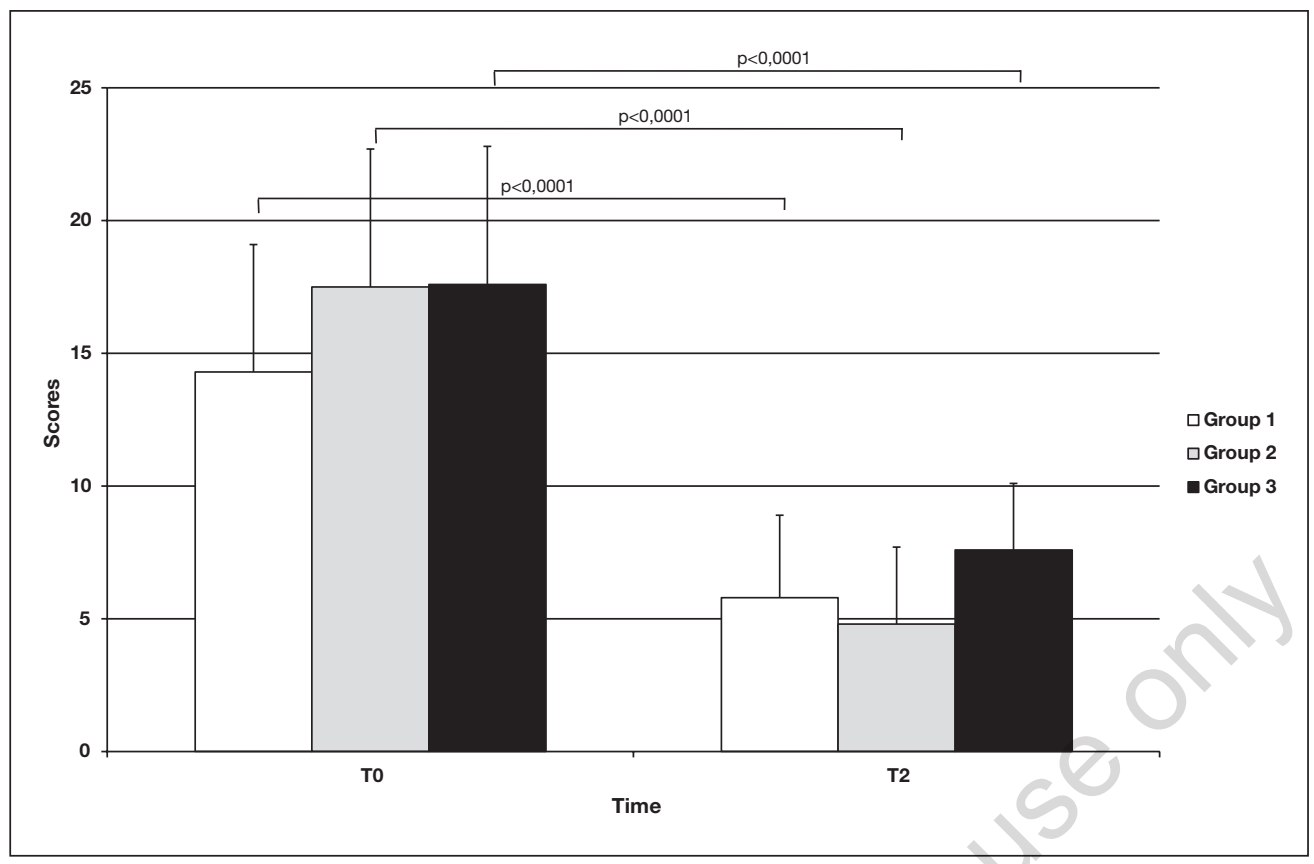

Figure 4 - Level of the quality of life in the three groups after one month of treatment (long term test) (data are expressed as mean score \pm SEM).

showed highly significant data concerning hydration of the skin stratum corneum $(\mathrm{P}=0.0012)($ Tab. I).

\section{DISCUSSION AND CONCLUSIONS}

$\mathrm{SSc}$ is a rare heterogeneous connective tissue disorder that is characterized primarily by abnormal collagen deposition in the skin and internal organs. Skin manifestations are important symptoms leading to early diagnosis of SSc and its differentiation into $\mathrm{lcSSc}$ and dcSSc, the two major clinical subsets of SSc, as well as differentiation from scleroderma-related disorders. There are many disabling cutaneous manifestations of SSc, which constitute a major burden for patients and severely affect their quality of life; whenever and wherever possible, they should be treated. A range of treatment options is available for management of SSc skin manifestations such as dry skin, telangiectases, skin pigmentation changes, calcifications and digital ulcers. However, the evidence for most treatments is limited. Nowadays there are no specific products for the skin of patients affected by SS that respect and protect the skin during cleansing and provide a deep moisturizing and soothing action. The study carried out on the two products showed that the daily use of cosmetic formulations is recommended to cleanse and take care of the skin of scleroderma patients. Indeed, no allergic reactions or intolerance have been reported. The cleanser preserves in particular the skin phospholipid bilayer, providing protective, moisturizing and humectant agents to the skin.

Results obtained in group 1 and 2 with reference to TEWL and Moisture showed a significant reduction in trans epidermal water loss. This fact proves that the simultaneous treatment with the cleanser and the cream, in addition to intravenous Iloprost therapy, is effective in strengthening the skin barrier function in scleroderma patients. On the basis of obtained data, it is possible to suppose that intravenous therapy with Iloprost favors the absorption of active principles contained in the moisturizing cream. The role of ceramide III, contained in the moisturizing cream, is considered to be fundamental for the results obtained on trans epidermal water 
loss, because it acts by binding epidermal cells. From the obtained data, cutaneous hydration very significantly increased in the three study groups in the short-term test. This can be attributed to the presence of humectant substances in the two formulations under investigation. Also with reference to the long-term test, group 2 and group 3 showed very significant results.

Skin score evaluations obtained from the analysis of 17 cutaneous sites by doctors involved in the study underlined very significant improvement in group 1 and group 2 only. Data collected from questionnaires DLQI are very interesting, because they show a clear improvement in quality of life of scleroderma patients, who underwent three different treatments. In particular, a better subjective perception of tactile sensation and minor discomfort in the pathological skin have been reported.

Definitively, the simultaneous use of the two formulations proved to be an effective adjuvant treatment to the general therapy (Iloprost) in scleroderma patients, determining an improvement in the general hydration of the skin and in the quality of life in terms of interpersonal relationships and spontaneity of behavior.

It would be interesting to assess the possible reduction of skin discomfort in patients affected by scleroderma using the treatments analyzed in this study, in different seasons and at different temperatures.

Conflict of interests: the authors report no conflict of interests.

\section{REFERENCES}

1. Tamby MC, Chanseaud Y, Guillevin L, Mouthon L. New insights into the pathogenesis of systemic sclerosis. Autoimmun Rev. 2003; 2: 152-7.

2. Servettaz A, Agard C, Tamby MC, Guilpain P, Guillevin L, Mouthon L. Systemic sclerosis: pathophysiology of a multifaceted disease. Press Med. 2006; 35: 1903-15.

3. Casale R, Buonocore M, Matucci-Cerinic M. Systemic sclerosis (scleroderma): an integrated challenge in rehabilitation. Arch Phys Med Rehabil. 1997; 78: 767-73.
4. Leroy EC, Black C, Fleischmajer R, Jablonska S, Krieg T, Medsger TA Jr, et al. Scleroderma (systemic sclerosis): classification, subsets and pathogenesis. J Rheumatol. 1988; 15: 202-5.

5. Gintrac M. Note sur la sclerodermie. Rev Med Chir Paris. 1847; 2: 263-81.

6. Masi A, Rodnan G, Medsger T. Preliminary criteria for the classification of systemic sclerosis (scleroderma). Subcommittee for scleroderma criteria of the American Rheumatism Association Diagnostic and Therapeutic Criteria Committee. Arthritis Rheum. 1980; 23: 581-90.

7. Robert-Thomson PJ, Mould TL, Walker JG, Smith MD. Clinical utility of telangiectasia of hands in scleroderma and other rheumatic disorders. Asian Pac J Allergy Immunol. 2002; 20: 7-12.

8. Ingraham KM, Steen VD. Morbidity of digital tip ulcerations in scleroderma. Arthritis Rheum. 2006; 54:F78.

9. Ferri C, Valentini G, Cozzi F, Sebastiani M, Michelassi C, La Montagna G, et al. Systemic Sclerosis Study Group of the Italian Society of Rheumatology (SIR-GSSSc). Systemic sclerosis: demographic, clinical, and serologic features and survival in 1,012 Italian patients. Medicine (Baltimore). 2002; 81: 139-53.

10. Krieg T, Takehara K. Skin disease: a cardinal feature of systemic sclerosis Rheumatology. 2009; 48:iii14-8.

11. Medsger Jr TA. Treatment of systemic sclerosis. Ann Rheum Dis. 1991; 50: 877-86.

12. Erre GL, Passiu G. Antioxidant effect of Iloprost: current knowledge and therapeutic implications for systemic sclerosis. Reumatismo. 2009; 61: 90-7.

13. Scorza R, Caronni M, Mascagni B, Berruti V, Bazzi S, Micallef E, et al. Effects of long-term cyclic iloprost therapy in systemic sclerosis with Raynaud's phenomenon. A randomized, controlled study. Clin Exp Rheumatol. 2001; 19: 503-8.

14. Steen VD, Medsger TA. Improvement in skin thickening in systemic sclerosis associated with improved survival. Arthritis Rheum 2001; 44: 2828-35.

15. Morton SJ, Powell RJ. Cyclosporin and tacrolimus: their use in a routine clinical setting for scleroderma. Rheumatology. 2000; 39: 865-9.

16. Valentini G, Paone C, La Montagna G, Chiarolanza I, Menegozzo M, Colutta E, et al. Lowdose intravenous cyclophosphamide in systemic sclerosis: an open prospective efficacy study in patients with early diffuse disease. Scand J Rheumatol. 2006; 35: 35-8.

17. Basso M, Filaci G, Cutolo M, Murdaca G, Derchi L, Gianrossi R, et al. Long-term treat- 
ment of patients affected by systemic sclerosis with cyclosporin A. Ann Ital Med Int. 2001; 16: 233-9.

18. Vanthuyne M, Blockmans D, Westhovens R, Roufosse F, Cogan E, Coche E, et al. A pilot study of mycophenolate mofetil combined to intravenous methylprednisolone pulses and oral low-dose glucocorticoids in severe early systemic sclerosis. Clin Exp Rheumatol. 2007; 25: 287-92.

19. Klingman A. Introduction: perspectives and prospects in dry skin and moisturizers chemistry and function. Boca Raton, FL: CRC Press; 2006; 1-4.
20. Del Rosso JQ. Cosmeceutical moisturizers. In: Draelos ZD, ed. Procedures in cosmetic dermatology series: Cosmeceuticals. 1st ed. Philadelphia, PA: Elsevier; 2005; 97-102.

21. Clements P, Lachenbruch P, Seibold J, Wigley FM. Inter-and intra-observer variability of total skin thickness score (modified Rodnan) in Systemic Sclerosis (SSc). J Rheumatol. 1995; 22: 1281-5.

22. Finlay AY, Khan GK. Dermatology Life Quality Index (DLQI): a Simple practical measure for routine clinical use. Clin Exp Dermatol. 1994; 19: 210-6. 